\title{
Erratum to: Conductivity Sensors Based System Development and Application to Investigate the Interfacial Behaviour between Supersonic Steam Jet and Water
}

\author{
Afrasyab Khan $^{a, *}$, Khairuddin Sanaullah ${ }^{b}$, E. K. Spiridonov ${ }^{a}$, A. V. Podzerko ${ }^{a}$, \\ D. F. Khabarova ${ }^{a}$, Ahmad Hasan Ali ${ }^{a}$, Ahmad Salam Farooqi ${ }^{c, d}$, Mohammed Zwawie, \\ Mohammed Algarni ${ }^{e}$, Bassem F. Felemban $f$, Ali Bahadar ${ }^{g}$, Atta Ullah ${ }^{h}$, and Bawadi Abdullah ${ }^{i, j}$ \\ ${ }^{a}$ Polytechnic Institute of South Ural State University (National Research University), \\ Chelyabinsk, 454080 Russia \\ ${ }^{b}$ Department for Management of Science and Technology Development, Faculty of Applied Sciences, Ton DucThang University, \\ Ho Chi Minh City, Vietnam \\ ${ }^{c}$ Department of Chemical Engineering, University Technology Petronas, Bandar Seri Iskandar, \\ Perak, 32610 Malaysia \\ ${ }^{d}$ Department of Chemical Engineering, Wah Engineering College, University of Wah, \\ WahCantt, Punjab, 47040 Pakistan \\ ${ }^{e}$ Department of Mechanical Engineering, King Abdulaziz University, \\ Rabigh, 21911 Saudi Arabia \\ ${ }^{f}$ Mechanical Engineering Department, Taif University, \\ Taif, 26571 Saudi Arabia \\ ${ }^{g}$ Department of Chemical and Materials Engineering, King Abdulaziz University, \\ Rabigh, 21911 Saudi Arabia \\ ${ }^{h}$ Department of Chemical Engineering, Pakistan Institute of Engineering and Applied Sciences (PIEAS), \\ Nilor, Islamabad, Pakistan \\ ${ }^{i}$ Chemical Engineering Department, Universiti Teknologi PETRONAS, \\ Seri Iskandar, 32610 Malaysia \\ ${ }^{j}$ CCentre of Contaminant Control and Utilization (Cen CoU), Institute of Contaminant Management for Oil and Gas, \\ Universiti Teknologi PETRONAS, Seri Iskandar, 32610 Malaysia \\ *e-mail: khana@susu.ru; drafrasyabkhan7@gmail.com \\ Received August 23, 2021
}

DOI: $10.1134 / \mathrm{S} 0020441221050249$

The name of the seventh author should read Ahmad Salam Farooqi.

The original article can be found online at

https://doi.org/10.1134/S0020441221040126 